\title{
Aspectos éticos em uma disputa de mercado entre laboratórios clínicos e um plano de saúde: relato de caso
}

\author{
Ethical issues in a market dispute \\ between clinical laboratories and a health plan - case report
}

M alone Santos Pinheiro ${ }^{1}$

Ana M aria Guedes de Brito ${ }^{1}$

Verônica de Lourdes Sierpe Jeraldo ${ }^{1}$

Kariny Souza Pinheiro 2

${ }^{1}$ Laboratório Central de Biomedicina, Centro de

Ciências Biológicas e da

Saúde, Universidade

Tiradentes. Rua Laranjeiras

726, Centro. 49000-000

Aracaju SE.

malonepinheiro@

hotmail.com

${ }^{2}$ Instituto de Tecnologiae

Pesquisa.

Abstract In Brazil the private health plans appear as an alternative to the public health assistance. This segment suffered great intensification in the seventies and eighties, culminating in the entry of large insurance company in the scenario of supplementary medicine. Quickly, the service providers associated with these insurance companies, consolidating them in themarket and triggering a relationship of dependency. This article analyzed, in the form of a case report, a marketing dispute between clinical laboratories and a health plan, emphasizing the moral and ethical aspects involved in this episode.

Key words Marketing dispute, Clinical laboratories, Private health plans, Ethical aspects
Resumo Como alternativa à assistência em saúde pública, surgem no Brasil os planos privados. Esse segmento sofreu grande intensificação nas décadas de setenta e oitenta, culminando com a entrada das grandes seguradoras no cenário da medicina suplementar. Rapidamente, os prestadores de serviço se associaram a elas, solidificando-as no mercado e desencadeando uma relação de dependência. 0 presente artigo analisou, em forma de relato de caso, uma disputa mercadológica entrelaboratórios clíni cos eum plano de saúde, enfatizando os aspectos éti cos e morais envolvidos nesse episódio.

Palavras-chave Disputa mercadológica, Laboratórios clínicos, Planos privados de saúde, Aspectos éticos 


\section{Introdução}

A vertente da saúde que compreende os laboratórios de análises clínicas vem passando por mudanças no que concerne às disputas mercadológicas. Um fator crucial na construção desse cenário é indubitavelmente a expansão dos planos de saúde privados ${ }^{1}$.

Esse fenômeno é explicado pelos gestores dos planos como sendo uma melhor alternativa de assistência à saúde, já que o Sistema Ú nico de Saúde (SUS) não oferecia condições plenas de assistência aos seus usuários, quiçá pela grande procura e a evolução deles no que diz respeito à qualidade?

$\mathrm{N}$ a década de oitenta, havia cerca de quinze milhões de segurados de planos de saúde particulares, registrados pela Associação Brasileira de M edicina deGrupo (ABRAM GE), bem como pela Federação das Cooperativas M édicas (UNIM ED). Esses números revelavam a consolidação das empresas de planos de saúde como alternativas assistenciais para os trabal hadores especializados, fato esse que ocorreu inicialmente na Região Sudeste e posteriormente se expandiu para todo o território brasileiro ${ }^{3}$.

H ouvea intensificação da comercialização de planos individuais, culminando com a entrada decisiva de grandes seguradoras no ramo da saúde, a adesão de novos grupos de trabalhadores à assistência médica supletiva - em particular, funcionários públicos da administração direta, das autarquias e das fundações - e a vinculação inequívoca da assistência privada ao financiamento da assi stência médica suplementar ${ }^{4}$.

Com o advento supracitado, ocorreu também uma grande procura por parte das empresas prestadoras de serviço em saúde, notadamente pela progressiva escassez dos pacientes particulares e crescente deterioração do relacionamento com a área pública (defasagem acentuada e crescente de preços, glosas, atrasos nos pagamentos, tetos físicos efinanceiros incompatíveis com o volume dos serviços prestados, entre outros), que não relutaram em compor uma associação forte e firme com as operadoras de planos de saúde4.

No início da década de noventa, os médicos já registravam uma enorme dependência das operadoras de planos de saúde, dados esses compilados pela Escola Nacional de Saúde Pública, apontando que $75 \%$ a $90 \%$ dos médicos declaravam depender diretamente dos convênios para manter suas atividades em consultório ${ }^{5}$.

0 presente estudo buscou analisar através de um relato de caso as relações existentes entre os planos de saúde e prestadores de serviço, mais especificamente laboratórios de análises clínicas, dando ênfase aos aspectos morais eéticos, salvaguardando as suas reais razões sociais e região onde ocorreram os fatos relatados.

\section{Relato decaso}

Em uma determinada cidade do Brasil, ocorreu uma disputa de mercado muito acirrada no âmbito das análises clínicas. Um determinado laboratório "A" (LAB-A), detentor de aproximadamente $70 \%$ do mercado na região, adotou uma postura bastante aguerrida na disputa mercadológica, propondo ao maior plano de saúde daquela área uma parceria.

Nesse acordo bilateral, o LAB-A passaria uma parcela de suas ações ao plano, tornando-se então um prestador de serviço próprio dele, o que os isentaria de uma possível caracterização de monopólio perante a lei. 0 resultado do acordo entre as empresas foi firmado com a criação de uma terceira empresa, na qual os sócios participariam com ações iguais. A partir de então, 0 LAB-A/plano tornou-se o único prestador de serviços no âmbito de análises clínicas para 0 citado plano, que por sua vez receberia grandes descontos nos preços dos exames solicitados.

Concretizada essa parceria, todos os outros laboratórios deanálises clínicas foram descredenciados a atender os usuários do plano. Um segundo laboratório, LAB-B, concorrente mais próximo do LAB-A, responsável por aproximadamente $20 \%$ dos atendimentos do referido plano de saúde, com o estabelecimento dessa parceria, sofreu grande impacto, perdendo nesse momento $50 \%$ da sua demanda e $40 \%$ do seu faturamento.

Diante desse quadro, 0 gestor do LAB-B convocou uma reunião com os gestores de outros laboratórios também prejudicados por essa medida, a fim de discutirem possíveis al ternativas. Houve a reunião, mas não chegaram a um denominador comum, nem tampouco ficou estabelecida comissão para representá-los frente à possível reunião com o gestor do plano.

Diante do impasse, o gestor do LAB-B reuniuse com o diretor do plano, a fim de expor as suas dificuldades, inclusivepor recentementeter investido na certificação do seu laboratório por um órgão internacional eestar precisando de um tempo para restabelecer seu equilíbrio financeiro, bem como os problemas sociais em relação aos seus funcionários e, também, a necessidade de prestar serviço à comunidade da qual faz parte. Diante do exposto, o plano desaúdeconcedeu mais três meses deatendimento a todos os laboratórios descredenciados. 
Temendo represálias dos seus usuários, pela falta de opções de escolha, o plano permitiu que alguns laboratórios de pequeno porte atendessem; todavia, excluiu os laboratórios mais estruturados, inclusive o LAB-B.

Em meio aos acontecimentoso diretor do LAB$B$ viu-seem sérias dificuldades, devido à subutilização dos seus serviços pela perda do referido plano. Esselaboratório, caracterizado como demédio porte na cidade, com quinze anos de funcionamento, possuía 22 funcionários.

N esse momento, entra em questão a responsabilidade social da empresa e o dilema de como manter-se no mercado de forma viável, sem demitir colaboradores e diminuir seu compromisso com a qualidade dos serviços prestados.

Após refletir, o gestor do LAB-B não enxergou no momento outra alternativa senão cortar custos e começou a demitir funcionários. Durante certo tempo, esse laboratório sofreu grave crise com problemas de ordem financeira decorrentes da associação do seu concorrente com sua maior fonte de renda.

Para não sucumbir de vez, o gestor do LAB-B resolveu propor sociedade a um grande grupo médico da cidade; nesse acordo, venderia parte de suas ações a ele e, a partir de então, ganharia o direito de atender os usuários do plano acima citado, já que o gestor do grupo médico era um dos conselheiros do plano, queno seu estatuto interno impedia o descredenciamento de conselheiros.

Com essa sociedade, o LAB-B passa então a atender os usuários do plano, encontrando assim uma alternativa viável de sobrevivência diante de um cenário adverso.

\section{Análiseética do caso exposto}

Existem várias definições deética; para M oore ${ }^{6}$ ética é a investigação geral sobre aquilo que é bom. Segundo Valls ${ }^{7}$, a ética é daquelas coisas que todo mundo sabe o que são, mas que não são fáceis de explicar, quando alguém pergunta, e mais contemporaneamente, Galvão ${ }^{8}$ sugere que a ética vai além do trato das ciências médicas, tornando-se uma ferramenta de reflexão para todas as relações existentes entre seres humanos.

Com baseno caso exposto, podem-se identificar algumas atitudes antiéticas adotadas pelas empresas envolvidas na disputa e defesa de interesses em um contexto de mercado altamente competitivo e capitalista.

$\mathrm{Na}$ associação entre o LAB-A e o plano, ficam caracterizadas ações que vão de encontro à ética, pois na tomada dessa decisão foram levados em consideração aspectos simplesmente financeiros e humanamente egocêntricos, o que desencadeou impacto social, e com a criação da terceira empresa, ficou caracterizado o intuito de burlar a lei e enganar a sociedade na tentativa de obscurecer o monopólio nesse setor.

0 plano em questão tornou-se extremamenteantiético no momento em queimpediu queseus usuários exercessem o direito da livre escolha dos serviços de sua preferência e, também, com os outros laboratórios da região que dependiam de seus segurados para seu pleno funcionamento.

Ficou explícita a falta de ética profissional do LAB-A para com todos os laboratórios, no momento do selamento do acordo com o plano, em queele exigiu o descredenciamento dos seus concorrentes.

N ovamente, o plano tornou-se não ético, quando coloca os laboratórios de pequeno porte como "testas de ferro", tentando silenciar seus segurados e enfraquecendo o poder de reivindicação dos laboratórios melhores estruturados.

$E m$ relação à situação do $L A B-B$, entendeuse que seu gestor viu-se praticamente obrigado, devido aos problemas acarretados com o descredenciamento e o que isso acarretou de uma forma geral em sua empresa, a tomar atitudes que, também de certa forma, são um comportamento antiético, no momento em que houve a fusão com o grupo médico da região.

Ficou claro no relato queo capitalismo selvagem imperou como um obstáculo para o pleno exercício da ética, bem como o fato de que um comportamento antiético pode desencadear vários outros.

\section{Consideraçõesfinais}

A ética empresarial não consiste somente no conhecimento da palavra ética, mas na sua prática constante. Esse praticar concretiza-se no campo comum da atuação diária e não apenas em ocasiões próprias ou excepcionais geradoras de conflitos deconsciência. Ser ético não significa conduzirseeticamentequando for conveniente, mas em cada decisão a ser tomada.

Portanto, faz-se importante entender que todos devem ter um compromisso com a existência da vida etudo que por el a perpassa, de forma a compreender a ética como uma reflexão sobre tudo aquilo que se refere ao ser, desde 0 ar que respira, o solo que pisa, a água que bebe e a qualidade do seu habitat. 


\section{Colaboradores}

MS Pinheiro, AM G de Brito, KS Pinheiro e VLS Jeraldo participaram igualmente de todas etapas de elaboração do artigo.

\section{Referências}

1. Bahia L. Planos privados de saúde: luzes e sombras no debate setorial dos anos 90. Cien Saude Colet 2001; 6(2):329-339.

2. Zucchi P, Del Nero C, Malik AM. Gastos em saúde: os fatores que agem na demanda e na oferta dos serviços de saúde. Saude soc. 2000; 9(1/2):127-150.

3. Bahia L, Costa AJL, Fernandes C, Luiz RR, Cavalcanti M LT. Segmentação da demanda dos planos e seguros privados de saúde: uma análise das informações da PNAD/98. Cien Saude Colet 2002; 7(4):671-686.

4. Silva AA. Relação Entre O peradoras de Planos de Saúde e Prestadores de Serviços - U m Novo Relacionamento Estratégico. Brasília: M inistério da Saúde; 2003.

5. Machado MH. Perfil dos M édicos no Brasil: Relatório final. Volume IV. Rio de Janeiro: Fiocruz/CFM M S/PNUD; 1995

6. Moore GE. Princípios éticos. São Paulo: Abril Cultural; 1975.

7. Valls ALM . O que é ética? São Paulo: Brasiliense; 1993.

8. Galvão AM. Bioética: ética a serviço da vida. Aparecida: Santuário; 2004.

Artigo apresentado em 02/01/2008

A provado em 03/03/2008

Versão final apresentada em 29/04/2008 